Article

\title{
Analysis of Toxigenic Fusarium Species Associated with Wheat Grain from Three Regions of Russia: Volga, Ural, and West Siberia
}

\author{
Tatiana Gagkaeva ${ }^{1,2, *(\mathbb{D},}$, Olga Gavrilova ${ }^{1}{ }^{(\mathbb{C}}$, Aleksandra Orina ${ }^{1}$, Yuri Lebedin ${ }^{3}$, Ilya Shanin ${ }^{3}$, \\ Pavel Petukhov ${ }^{3}$ and Sergei Eremin ${ }^{4}$ (I) \\ 1 Laboratory of Mycology and Phytopathology, All-Russian Institute of Plant Protection, St. Petersburg, \\ 196608 Pushkin, Russia; olgavrilova1@yandex.ru (O.G.); orina-alex@yandex.ru (A.O.) \\ 2 The Institute of Environmental and Agricultural Biology (X-BIO), University of Tyumen, 625003 Tyumen, \\ Russia \\ 3 XEMA Company Limited, 105264 Moscow, Russia; info@xema-medica.com (Y.L.); \\ info@xema-medica.com (I.S.); info@xema-medica.com (P.P.) \\ 4 Chemical Department, M.V. Lomonosov Moscow State University, 119991 Moscow, Russia; \\ eremin_sergei@hotmail.com \\ * Correspondence: t.gagkaeva@yahoo.com; Tel.: +7-812-333-3764
}

Received: 27 March 2019; Accepted: 2 May 2019; Published: 5 May 2019

\begin{abstract}
Wheat grains collected in three regions of Russia-Volga, Ural, and West Siberia-were analyzed for triangulation of methods in analysis of toxigenic Fusarium species. The presence of fungi and quantitative content of their biomass were detected by using various analytical methods, including a mycological and immunochemical methods, and quantitative PCR. Additionally, an enzyme-linked immunosorbent assay and high-performance liquid chromatography with tandem mass spectrometry were applied for determination of mycotoxins. Regional differences were found regarding the contamination of wheat grain by Fusarium fungi and their toxins. The most important observation was the detection of F. graminearum in the Ural and West Siberian regions, where this pathogen had not been found previously. A maximum damaged grains by F. graminearum and F. sporotrichioides was found in the grain samples from West Siberia. The DNA of F. graminearum was detected in $19.2 \%$ and DNA of F. sporotrichioides was found in $84.1 \%$ of the analyzed grain samples. The amount of Fusarium antigens in the grain samples from the West Siberian region was 7-8 times higher than in the grain samples from the other two regions. Significant contamination of the grain with deoxynivalenol and T-2/HT-2 toxins (maximum contents were $2239 \mathrm{ppb}$ and $199 \mathrm{ppb}$, respectively) was detected in the West Siberian region.
\end{abstract}

Keywords: Fusarium fungi; Russia; wheat grains; DNA; biomass; mycotoxins; qPCR; immunoassay; HPLC-MS/MS

Key Contribution: Wheat grains collected in Russia were analyzed for Fusarium infection using a mycological method; quantitative PCR; and immunochemical analysis. The same samples were tested for mycotoxins by ELISA and HPLC-MS/MS. F. graminearum infection was revealed in the grain samples from Ural and West Siberian regions. The presence of $F$. sporotrichioides DNA was found in $84.1 \%$ of the analyzed grain samples. In addition, in all regions a significant contamination of the grain samples with deoxynivalenol and T-2/HT-2 toxins was detected. 


\section{Introduction}

Fusarium Link is a large cosmopolitan genus of ascomycete fungi consisting of numerous species that are both saprotrophic and pathogenic to cereals. The major impacts of pathogenic species on wheat include a yield reduction as well as a reduction in the marketable quality of grains.

Some Fusarium species are known to produce different types of mycotoxins, which are the most deleterious of natural metabolites in terms of health effects. The ability to produce mycotoxins varies between species and also between strains of the same species, but the quantity of formed metabolites depends on environmental factors. Research on the Fusarium problem in cereals has demonstrated that visual symptoms, fungal incidence, and mycotoxin accumulation in grains are not always closely linked [1-3]. Due to the problem of Fusarium damaged grain (FDG), there is a need for highly accurate methods for detecting the infection of grain batches and quantitative mycotoxin contamination.

It is known that several Fusarium species can be found together in a grain sample and even in a single grain $[4,5]$. The most important mycotoxin producers in small grain cereals are F. graminearum Schwabe, F. sporotrichioides Sherb., and F. langsethiae Torp and Nirenberg [6-8]. It is well known that F. graminearum is the main producer of trichothecenes type B (mostly deoxynivalenol, DON), while F. sporotrichioides and F. langsethiae are associated with trichothecenes type A (mostly T-2 and HT-2 toxins) [9]. Some strains of $F$. graminearum concomitantly produce another mycotoxin, zearalenone (ZEN), which shows estrogenic activity [10]. As was noticed, the climate changes have a significant impact on stages and rates of toxigenic fungi development and can modify host-pathogen interactions, also deeply influencing the conditions for mycotoxin production [11].

In light of the ubiquity and health hazards presented by some secondary metabolites of Fusarium fungi, many countries have introduced mandatory or guideline levels for mycotoxins in grain and grain-based products. In the Russian Federation on the legislation regarding mycotoxins in wheat grain for direct human consumption the maximum permissible levels for T-2 toxin is $100 \mathrm{ppb}$, for DON is $700 \mathrm{ppb}$, and for ZEN is $1000 \mathrm{ppb}$ [12]. Often the time interval is very short between obtaining the harvested grain and the decision about its intended purpose, subsequent technological processing, and ultimately, the cost. The need for such large-scale analysis of grain led to the development and validation of numerous analytical methods utilizing a number of techniques.

The identification of the microbiological quality of grain includes two tasks, which are usually solved using fundamentally different methods. The first is the mycological identification of pathogenic Fusarium fungi remaining in the grains, while the second involves the quantitative detection of the metabolites that are obviously absent in plant tissue but inherent in fungi.

Traditional mycological methods, based on the stimulation of fungi growth on a nutrient medium and subsequent microscopic analysis, help to identify the spectrum of cultivated microorganisms and determine the frequency of grain infection with a specific taxon. The standard parameter used to characterize the purity of grain is the percentage of infected grain. However, it has long been acknowledged that the established percentage of grain infection is often weakly related to the quantitative presence of pathogen biomass [13,14].

Another possibility is the characterization of infection based on the number of metabolite markers of fungi that colonize the plant. For this purpose, it is possible to use the quantitative presence of both primary (e.g., proteins, fats, carbohydrates, and nucleic acids) and secondary (e.g., antibiotics, mycotoxins, and pigments) metabolites of a particular taxon.

Quantitative PCR (qPCR), which reveals the amount of DNA of one or a group of closely related microorganisms is quite popular in plant pathological research [15-17]. Another indirect method for assessing the toxicity of grain is the immunochemical discovery of antigens (EIA) that are produced by fungi during their vital activity [18-21].

Many strategies have been proposed for controlling the occurrence of mycotoxins in plants [22]. However, the analysis of mycotoxins is an arduous task, as they may occur in various combinations, are produced by a single or several fungal species, and are usually present in range concentrations. Currently, researchers widely utilize high-performance liquid chromatography with tandem mass 
spectrometry (HPLC-MS/MS) and enzyme-linked immunosorbent assays (ELISA) [23-27]. Regardless of the choice of analytical method, it should enable the rapid and sensitive detection of mycotoxins below the legally imposed limits. Moreover, it should be cost-effective and easy to use.

The aim of this study was to reveal the accuracy and precision of the information about F. graminearum and F. sporotrichioides infection and contamination by their mycotoxins of wheat grains from three regions of Russia using various analytical methods.

\section{Results}

The wheat grain samples were collected from three regions of Russia where, at present, information about grain infection and mycotoxin contamination of grown small grain cereals is limited in comparison to the southern and central parts of European Russia, which feature intense cereal production. It was first research of grain samples with using not only mycological method but additionally with the set of various analytical methods like as immunochemical methods, quantitative PCR and HPLC-MS/MS. A practical problem arises because a high proportion of a too-frequent zero value exists in data, in which case transformation to normality cannot be achieved. Therefore, it was used the other approaches not requiring a normal distribution like as the Mann-Whitney $\mathrm{U}$ test.

\subsection{Detection of Grain Infection with Fusarium Fungi}

Fusarium fungi were found in $47(82.5 \%)$ of the analyzed grain samples using the mycological method. The largest number of infected grain samples was detected in the West Siberian region (96.1\%), most of which were from Novosibirsk Oblast and Altai Krai, where the maximal percentage of FDG ranged from $35 \%$ to $38 \%$ (Table 1 ).

Table 1. Infection of the wheat grains by Fusarium fungi.

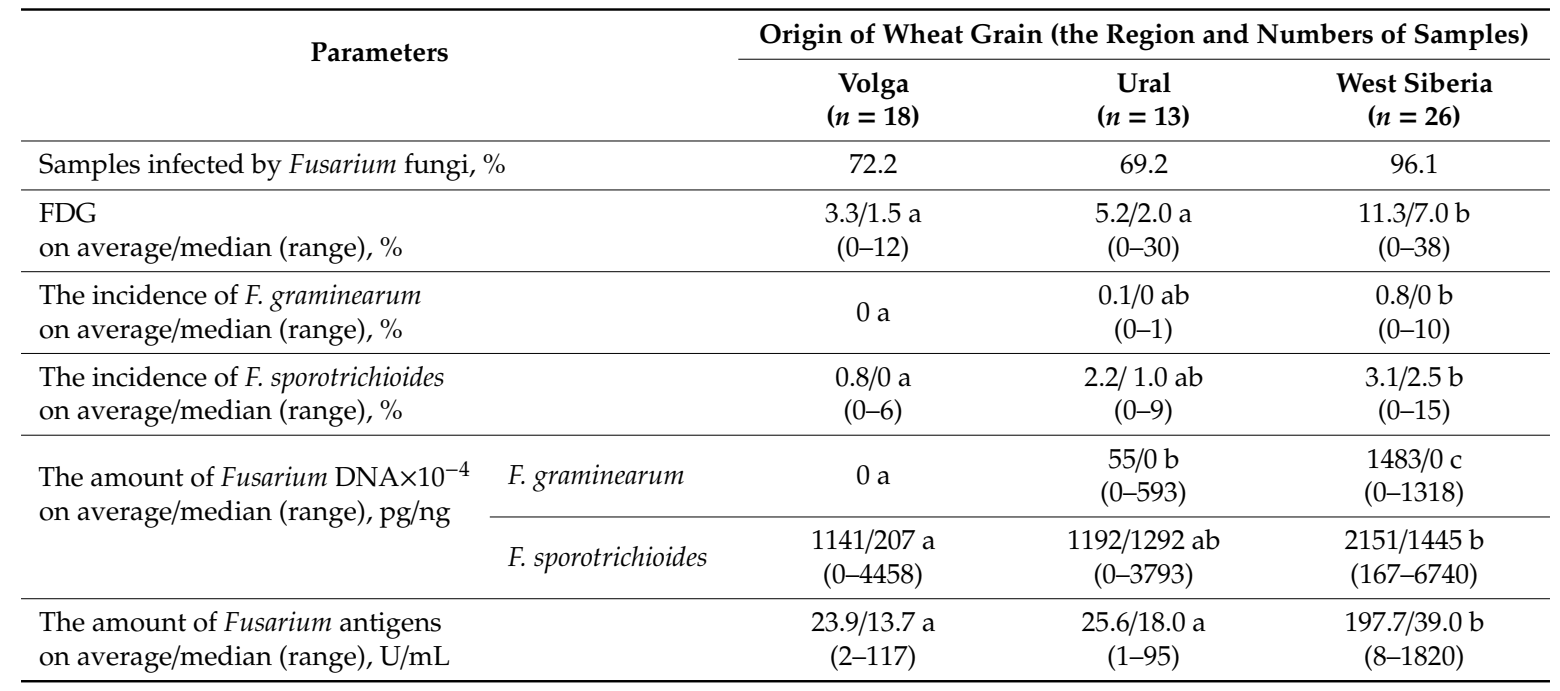

Medians indicated by the same letter in row are not statistically significantly different (Mann-Whitney U test; $p \leq 0.05)$.

F. graminearum was only detected in the grain samples from the Ural and West Siberian regions. The eight grain samples from Tyumen Oblast, Novosibirsk Oblast, Altai Krai, and Krasnoyarsk Krai were contaminated by this pathogen, with a maximum infection rate of $10 \%$.

The infection of grain by F. sporotrichioides was established in 33 wheat samples. The maximum of infection was found in the sample from Altai Krai from the West Siberian region (15\%). Conversely, the smallest amount of F. sporotrichioides infection was found in the Volga region (on average, less than $1 \%$ ).

In addition to F. graminearum and F. sporotrichioides, which produce trichothecenes, other species that are common contaminants of grains in this area were identified based on morphological characteristics: 
F. avenaceum (Fr.) Sacc., F. incarnatum (Desm.) Sacc., F. equiseti (Corda) Sacc., F. acuminatum Ellis \& Everh., F. poae (Peck) Wollenw., F. solani (Mart.) Sacc., and Fusarium spp.

\subsection{Quantification of Fusarium Biomass}

The DNA of F. graminearum was only detected in the grain collected in the Ural and West Siberian regions (30-31\% of samples). However, the average fungal DNA content was significantly higher in the grain samples from the West Siberian region, including several samples containing extremely high levels in Krasnoyarsk Krai (maximum F. graminearum DNA value was 1318 pg/ng of total DNA).

The DNA of F. sporotrichioides was detected in 100\% of the samples from West Siberia, $92.3 \%$ of the samples from the Ural region, and $61.1 \%$ of the samples from the Volga region. The fungal DNA content in the grain varied significantly. The maximum amount of $F$. sporotrichioides DNA was $6740 \mathrm{pg} / \mathrm{ng}$ of total DNA, which was found in a grain sample from Krasnoyarsk Krai. In addition, samples containing a significant amount of F. sporotrichioides DNA were found in Bashkortostan, Penza Oblast, Altai Krai, and Tyumen Oblast.

The Fusarium biomass revealed by the immunoassays in tested grain samples varied significantly from non-detectable amount to the concentrations exceeding the range of assay calibration curve $(>250 \mathrm{U} / \mathrm{mL}$ ). The average biomass content of Fusarium fungi in the grain samples collected in the Volga and Ural regions was similar and varied from 23.9 to $25.6 \mathrm{U} / \mathrm{mL}$ (on average, 13.7-18.8 U/mL). Further, the Fusarium biomass content in the grain samples from the West Siberian region was 7-8 times higher than that in the grain samples obtained from the other two regions.

\subsection{Detection of Fusarium Mycotoxins}

The results of mycotoxin analysis obtained by ELISA showed that one sample from the sets of grain collected in both the Volga and Ural regions contained DON in amounts near 100-150 ppb (Table 2). Among the grain samples from the West Siberian region, DON was detected in six samples. The maximum amount of this mycotoxin was 2787 ppb in grain from Krasnoyarsk Krai. ZEN was only found in three samples from the West Siberia in minor amounts. ELISA detected T-2 toxin in one grain sample in each region, with a maximum amount of 74 ppb (Chelyabinsk Oblast, the Ural).

Table 2. Fusarium mycotoxins content in the wheat grains from different regions estimated by ELISA and HPLC-MS/MS.

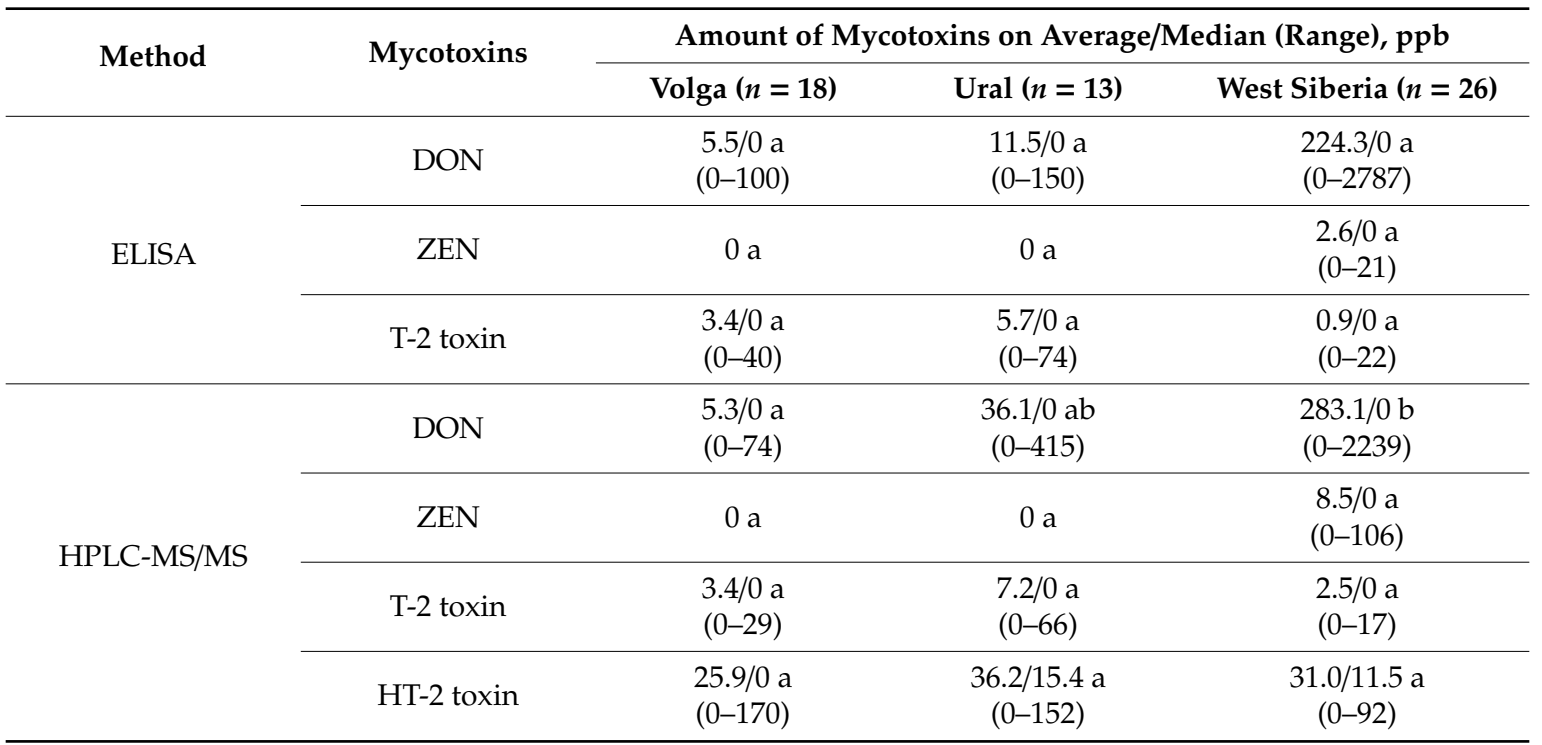

Medians indicated by the same letter in row are not statistically significantly different (Mann-Whitney U test; $p \leq 0.05$ ). 
Data from the HPLC-MS/MS analysis revealed the presence of DON in three samples from the Volga region (maximum $74 \mathrm{ppb}$ ) and five samples from the Ural region (maximum $415 \mathrm{ppb}$ ). In the West Siberian region, DON was detected in 12 samples (maximum $2239 \mathrm{ppb}$ ). ZEN was found in three samples from the West Siberian region, ranging from 42 to $106 \mathrm{ppb}$, with the highest amount in a grain sample from the Krasnoyarsk Krai. T-2 toxin was found in four samples from both the Volga and West Siberian regions (maximum $29 \mathrm{ppb}$ ) and in two samples from the Ural region (maximum $66 \mathrm{ppb}$ ). The incidence of HT-2 toxin was higher than that of T-2 toxin. This mycotoxin was detected in seven grain samples from the Volga region and in eight samples from the Ural region (maximum 152-169 ppb). Additionally, HT-2 toxin was found in 22 samples from the West Siberian region (maximum $92 \mathrm{ppb}$ ).

\subsection{Relationship between Fusarium Fungi Presence and Their Mycotoxins}

In the Fusarium fungi complex detected on the grain, on average the proportion of $F$. graminearum was not high (3.6\%); the proportion of F. sporotrichioides was significantly higher (28.2\%) (Figure 1). This indicated a high correlation between FDG and F. sporotrichioides infection $(r=+0.70)$ and the amount of DNA of this fungus $(r=+0.38)$ (Table 3 ).

At the same time, the results of the correlation analysis revealed a significant positive relationship between the F. graminearum infection of grains and the fungal DNA content $(r=+0.42)$ as well as total FDG $(r=+0.43)$. Apparently, any presence of this aggressive pathogen leads to a significant accumulation of its biomass in grains.

The F. graminearum DNA content is also highly associated with DON and ZEN contents detected by ELISA and HPLC-MS/MS $(r=+0.94-0.99)$. It should be noted that the mycotoxin analysis results using these two methods have showed significant similarity $(r=+0.93-0.99)$.

This was confirmed by the positive correlation of the antigens of Fusarium fungi detected in the grain using the competitive EIA method with F. graminearum infection $(\mathrm{r}=+0.38)$ and with F. graminearum DNA content $(\mathrm{r}=+0.98)$.

A comparative analysis of the quantitative content of the fungal biomass using different methods (qPCR and EIA) and the results of mycological analysis showed a positive relationship between the amount of Fusarium antigens and F. graminearum infection, but this relationship was not found with F. sporotrichioides infection. Nevertheless, the content of F. sporotrichioides DNA was also positively related to the amount of Fusarium antigens detected by EIA $(r=+0.56)$. The results demonstrate that the Fusarium biomass determined by using the EIA is related to the DON content $(r=+0.96-0.97)$.

In our study, no relationship was established between the amount of T-2 toxin, detected by ELISA and HPLC-MS/MS, and F. sporotrichioides infection of grain or between the DNA content of this pathogen and the amount of Fusarium antigens. However, the amount of HT-2 toxin was positively related to the amount of T-2 toxin detected using both methods $(r=+0.65-0.78)$.

Moreover, the amount of HT-2 toxin, as well as the sum of the T-2 and HT-2 toxins, is significantly related to the DNA content of the main producer F. sporotrichioides $(r=+0.54-0.57)$. 
Table 3. The relationships between the parameters of wheat grain contamination by Fusarium fungi and mycotoxins estimated using various methods.

\begin{tabular}{|c|c|c|c|c|c|c|c|c|c|c|c|c|}
\hline \multirow{2}{*}{\multicolumn{3}{|c|}{ Estimated Parameters }} & \multicolumn{3}{|c|}{$\begin{array}{c}\text { Infected Grain Measured by } \\
\text { Mycological Method }\end{array}$} & \multirow{2}{*}{\multicolumn{2}{|c|}{$\begin{array}{l}\text { Amount of DNA of Fusarium } \\
\text { Fungi Measured by qPCR }\end{array}$}} & \multirow{3}{*}{$\begin{array}{l}\text { Amount of Antigens } \\
\text { of Fusarium Fungi } \\
\text { Measured by EIA }\end{array}$} & \multicolumn{4}{|c|}{$\begin{array}{c}\text { Amount of Mycotoxins of Fusarium Fung } \\
\text { Measured by }\end{array}$} \\
\hline & & & \multirow{2}{*}{${\text { F. } \text { gram. }^{1}}^{1}$} & \multirow{2}{*}{ F. spor. } & \multirow{2}{*}{ FDG } & & & & \multicolumn{2}{|c|}{ ELISA } & \multicolumn{2}{|c|}{ HPLC-MS/MS } \\
\hline & & & & & & F. gram. & F. spor. & & DON & T-2 & DON & T-2 \\
\hline \multirow{3}{*}{\multicolumn{2}{|c|}{$\begin{array}{l}\text { Infected grain measured by } \\
\text { mycological method }\end{array}$}} & F. gram. & 1.0 & & & & & & & & & \\
\hline & & F. spor. & 0.24 & & & & & & & & & \\
\hline & & FDG & $0.43^{*}$ & $0.70 *$ & & & & & & & & \\
\hline \multirow{2}{*}{\multicolumn{2}{|c|}{$\begin{array}{l}\text { Amount of fungal DNA measured by } \\
\text { qPCR }\end{array}$}} & F. gram. & $0.42 *$ & -0.07 & 0.10 & & & & & & & \\
\hline & & F. spor. & 0.30 & $0.43 *$ & $0.38 *$ & $0.54^{*}$ & & & & & & \\
\hline \multicolumn{3}{|c|}{ Amount of antigens of Fusarium fungi measured by EIA } & $0.38^{*}$ & -0.08 & 0.13 & $0.98^{*}$ & $0.56^{*}$ & & & & & \\
\hline \multirow{5}{*}{ 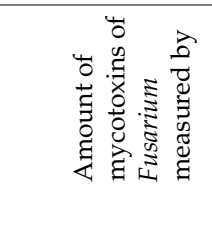 } & \multirow{2}{*}{ ELISA } & DON & 0.30 & -0.15 & 0.07 & $0.94 *$ & $0.53^{*}$ & $0.97 *$ & & & & \\
\hline & & $\mathrm{T}-2$ toxin & -0.06 & -0.05 & -0.04 & 0.10 & 0.22 & 0.12 & 0.15 & & & \\
\hline & \multirow{3}{*}{ HPLC-MS/MS } & DON & $0.45^{*}$ & -0.04 & 0.13 & $0.99 *$ & 0.55 * & $0.96^{*}$ & $0.93^{*}$ & 0.09 & & \\
\hline & & $\mathrm{T}-2$ toxin & 0.12 & 0.14 & 0.10 & 0.06 & 0.33 & 0.06 & 0.03 & 0.03 & 0.07 & \\
\hline & & HT-2 toxin & 0.11 & 0.24 & 0.13 & 0.06 & $0.57 *$ & 0.07 & 0.03 & 0.03 & 0.07 & $0.78^{*}$ \\
\hline
\end{tabular}

${ }^{1}$ F. gram.-F. graminearum, F. spor.-F. sporotrichioides, FDG—Fusarium damaged grain; ${ }^{*}$ Correlation coefficients are significant at $p \leq 0.01$. 


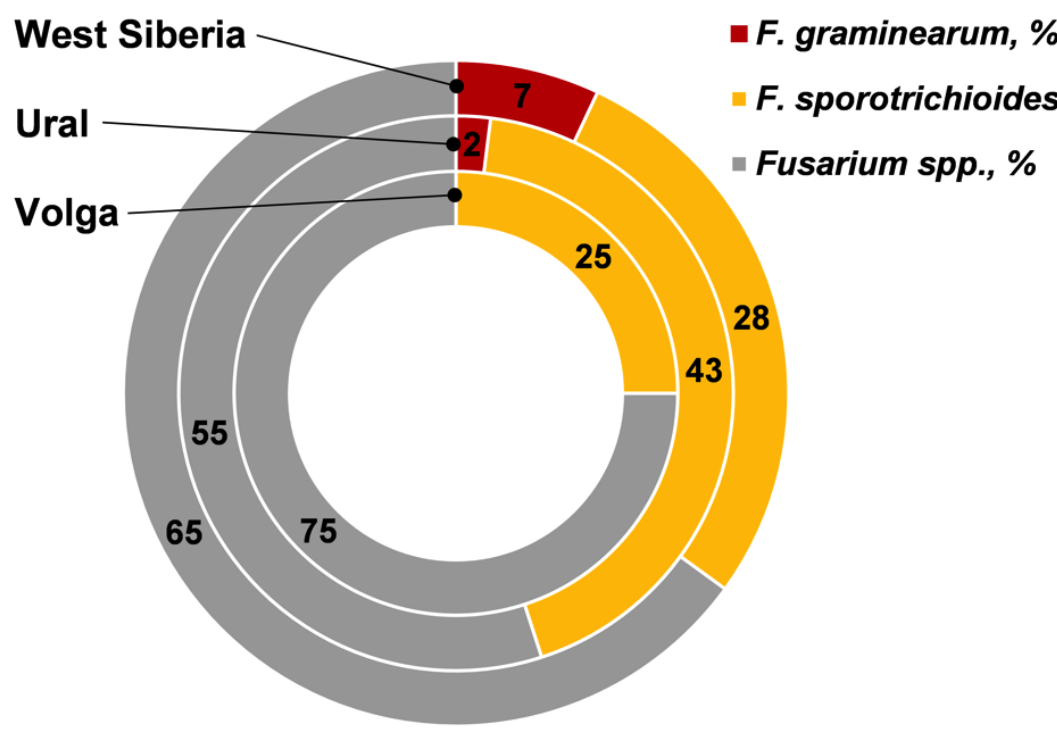

Figure 1. The relative proportions of F. graminearum and F. sporotrichioides in Fusarium fungi composition on wheat grain from the different regions of Russia.

\section{Discussion}

The using analytical methods provide the accuracy and correctness of the information, selection of the most effective strategies for the demonstration of existing situation with the toxin-producing fungi, which will be the platform for future researches. Despite the limited set of grain samples, we have shown the problem of Fusarium grain infection and mycotoxin contamination in the analyzed regions. The Ural Mountains have been considered the traditional boundary between Europe and Asia and can be a natural barrier to the spread of fungi between two parts of the continent. The vast territories extending from the Ural Mountains are characterized by contrasting climatic conditions, both territorial, and seasonal and daily. There is no doubt that a need for further studies of the quality of grain from these regions.

The consistent results obtained using the various analytical methods showed the presence of F. graminearum and its metabolites in wheat grains from the West Siberia (Novosibirsk Oblast, Altai Krai, and Krasnoyarsk Krai) and Ural regions (Tyumen Oblast). This is the first scientifically confirmed detection of $F$. graminearum in West Siberia. The grain samples with the highest rates of infection $(10 \%)$ were also characterized by a significant presence of F. graminearum DNA (up to $1318 \mathrm{pg} / \mathrm{ng}$ ). The F. graminearum infection in the grain from Krasnoyarsk Krai resulted in the accumulation of high amounts of DON more than 2-3 times the permissible level of $700 \mathrm{ppb}$ (up to $2787 \mathrm{ppb}$ ). The mycotoxin ZEN was also found in small amounts in these samples. Despite the detection of samples containing F. graminearum and the high level of infection of these samples, the median value of this pathogen in the grain from all the regions was very close to zero. However, it was found the significant differences between total FDG, F. graminearum infection and fungal DNA revealed in grains from West Siberian region in comparison with grain from Ural and especially Volga regions.

Until now, it was believed that only isolated populations of $F$. graminearum exist in Russia, one in the Far Eastern region and others in the south and northwest parts of European Russia [28,29]. The reason for this separation was the absence of this pathogen from the plants' mycobiota in Siberia [29-32]. The appearance of $F$. graminearum in West Siberia can be explained by various factors, including the possible introduction of the pathogen into the region with seeds or climate change [33].

It is known that rainfall and humidity during wheat flowering contribute to infection by F. graminearum [34]. In Table 4 provides summary analysis of temperature and precipitation for three summer months. In these regions, the flowering of spring wheat occurs in the first decade of July. The climate of Volga region is characterized by dry summer; in 2017 the amount of precipitation during three months was less than $71 \mathrm{~mm}$. In the Ural and West Siberia where F. graminearum was 
detected the average rainfall for these months was 131 and $113 \mathrm{~mm}$. In addition, the humidity during flowering and maturing of wheat in the Ural and West Siberia was higher than it was in the Volga region. The co-variability of measured data with observed monthly mean temperature and rainfall in the represented locations was determined. According to our data, the weather conditions only in August significantly influenced the outcome of the relationship between plants and Fusarium fungi. A positive relationship was established only between the amount of precipitation in August and the DNA content of F. graminearum, antigens and DON ( $p \leq 0.01)$. Increasing temperatures in August significantly reduced the total FDG, infection rate, and DNA content of $F$. sporotrichioides $(p \leq 0.01)$.

Previously it was shown that $F$. graminearum population dynamics have been influenced by a complex adaptive landscape comprising different regional selective pressures, and do not reflect a simple model of dispersal and integration following the introduction of a novel pathogen [35]. But we assume that the emergence of the aggressive pathogen F. graminearum on the territory where grain is cultivated implies the emergence of a problem with DON for years to come. It should be noted that the present data expands information about the area of $F$. graminearum in the global space and will get chance to acquainted with peculiarities of population of fungi.

Using the mycological method, the presence of F. sporotrichioides was established in $57.9 \%$ of the analyzed grain samples, whereas the DNA of this pathogen was found in $84.1 \%$ of the grain samples. In West Siberia, F. sporotrichioides was occurred in the $73.1 \%$ of samples with the average rate of grain infection 3.1\%, although the DNA content of the fungus was detected in all the samples and reached $2151 \mathrm{pg} / \mathrm{ng}$. Occurrence of this pathogen in West Siberia was significantly higher than in two others regions. F. sporotrichioides infection was detected in $33.3 \%$ of the samples from the Volga region and in $61.5 \%$ of the samples from the Ural region; the DNA of F. sporotrichioides was detected by qPCR in $61.1 \%$ and $92.3 \%$ of these samples, respectively.

At the same time, the occurrence of $F$. sporotrichioides did not lead to significant contamination of the grain with the mycotoxins and were not found the differences in amounts in the regions. T-2 toxin was detected in three of the samples analyzed by ELISA and in 12 samples using the HPLC-MS/MS method, with a content of less than $100 \mathrm{ppb}$. However, the analysis of its derivate HT-2 toxin using the chromatographic method led to its detection in 38 samples. This mycotoxin was detected in $84.5 \%$ of the grain samples from West Siberia, with a content of less than $100 \mathrm{ppb}$. In the Volga region, HT-2 toxin was found in $38.9 \%$ of the samples, and in the Ural region, it was found in $61.5 \%$ of the samples. In four of these samples (Bashkortostan, Tatarstan, and Chelyabinsk Oblast), the HT-2 toxin content was exceeded $100 \mathrm{ppb}$. These regions are notorious for an outbreak of a mycotoxin-induced disease in the 1930-40s known as alimentary toxic aleukia, which led to the deaths of thousands of people and animals [36]. Subsequently, the disease was determined to be caused by T-2 toxin produced by F. sporotrichioides growing on grains overwintered in the fields.

At a later date, when grain from West Siberia was analyzed with ELISA, the researchers noted the wide occurrence of this pathogen and a significant T-2-toxin content [37,38]. In all likelihood, the environmental conditions of this region contribute to the existence and spread of $F$. sporotrichioides. Indeed, a study of batches of wheat, barley, and oats harvested in 1995-2001 in the Ural region and in West Siberia using ELISA found T-2 toxin, on average, in 36.3\% (5.1-69.4\%) and 37.7\% (5.9-86.7\%) of the grain samples, respectively [38]. However, high levels of contamination exceeding the maximum allowable level were found in 2-3\% of the analyzed samples in each region.

The detection of significantly high amounts of HT-2 toxin in comparison to T-2 toxin in this study was unexpected. In the Russian Federation, a maximum permissible level has been established for T-2 toxin, and therefore mass screening of grain for this metabolite is carried out; however, HT-2 toxin is not usually investigated. This likely lead to an underestimation of the risk of grain contamination by F. sporotrichioides toxins. Our results highlight the need to consider the co-presence of T-2 and HT-2 toxins in grain.

Interestingly, a high correlation was found between the F. graminearum and F. sporotrichioides DNA contents in the grain, which also led to a significant correlation of DON and ZEN contents not 
only with the DNA of their producer F. graminearum but also with F. sporotrichioides DNA. One of the explanations for this phenomenon could be the similar susceptibility of cultivated wheat varieties, which, under favorable conditions for Fusarium infection, are not able to resist the penetration of all pathogenic species and thus the formation of mycotoxins.

The well-known producers of T-2 and HT-2 toxins are F. sporotrichioides, F. langsethiae, and F. sibiricum Gagkaeva, Burkin, Kononenko, Gavrilova, O’Donnell, and Aoki and Yli-Mattila [39,40]. In this study, we observed only F. sporotrichioides, although F. sibiricum previously has been detected in Siberia and the Russian Far East [40], and one strain of F. langsethiae has been found on Asian territory to date (the Ural region, Tyumen Oblast) [41]. The growth rate and biomass of aerial mycelium of F. langsethiae are significantly lower than those of F. sporotrichioides, so it is possible that during mycological analysis the colonies of this species were unnoticed under other fast-growing fungal colonies. Although we can only speculate, it appears that F. langsethiae and F. sibiricum may contribute to the contamination of grain with T-2 and HT-2 toxins in the Ural and the West Siberian regions. This opinion could be confirmed by the absence of high correlation between the amount of these mycotoxins and grain infection, F. sporotrichioides DNA content, and the results of all relevant immunoassays.

The observed often lack of relationship between the grain infection and the biomass of mycotoxins producer is quite an explicable. Depending on the time of infection, environmental conditions, and the susceptibility of the cultivar, the depth of the grain infection can vary significantly, as filaments of fungi can present on or in the surface layers or fully occupy the internal tissues of the endosperm [42,43].

In general, this study shows a need for further research on the Fusarium species capable of producing trichothecenes type A as well as the factors that affect mycotoxin production in grains, even though considerable progress has already been made in this area [44-48].

Development of accurate, rapid, specific, and easy protocols for early detection of the critical toxigenic Fusarium species will open up broad new fields of applications that could lead to improvements in healthy cereal production. Strict control of the contamination of grains used for food and feed is crucial for reducing the human and animal health risks related to mycotoxins.

\section{Conclusions}

For the first time, the Fusarium infection of wheat grain samples obtained from the Volga, Ural, and West Siberia regions of Russia were analyzed using highly sensitive analytical methods. Regional differences were identified regarding the contamination of wheat grain by Fusarium fungi and their toxins. The presence of F. graminearum and its toxic metabolites, such as DON and ZEN, in the Ural and West Siberia regions was confirmed. According to the ELISA and HPLC-MS/MS results, the DON content in wheat grain samples from West Siberia were 3-4 times higher than the permissible level. Simultaneously, the wide occurrence of F. sporotrichioides in the analyzed samples did not lead to significant contamination of the grain with the mycotoxins produced by this fungus. In addition, significantly higher levels of HT-2 toxin in comparison with T-2 toxin were found in the samples.

\section{Materials and Methods}

\subsection{Wheat Grain Samples}

In total, 57 wheat grain samples were collected from three regions of Russia (Volga, Ural, and West Siberia) and used for laboratory analyses (Table 4, Table S1). The Volga region (18 samples) was represented by Orenburg Oblast, Bashkortostan as well as Penza Oblast, Volgograd Oblast, Samara Oblast, and Tatarstan. The samples from the Ural region (13 samples) were collected in Chelyabinsk Oblast and Tyumen Oblast. The remaining 26 grain samples were collected in the West Siberian region: Altay Krai, Krasnoyarsk Krai, Novosibirsk Oblast, and Omsk Oblast.

All of the grain samples were harvested from commercial fields in 2017 and represented the different varieties of wheat recommended for cultivation in these regions (the effect of variety has not been taken into account in this study). 
Table 4. Climatic data during the growing season of 2017 in the regions of grain samples origin.

\begin{tabular}{ccccccc}
\hline \multirow{2}{*}{$\begin{array}{c}\text { Region } \\
\text { (Numbers of Samples) }\end{array}$} & Month & \multicolumn{2}{c}{ Average Month Temperature, ${ }^{\circ} \mathbf{C}$} & $\begin{array}{c}\text { Average } \\
\text { Humidity, \% }\end{array}$ & $\begin{array}{c}\text { Average } \\
\text { Rainfall, mm }\end{array}$ \\
\cline { 3 - 5 } & & Mean & Min & Max & & 34.0 \\
Volga & June & 20.3 & 10.4 & 30.1 & 56 & 28.9 \\
$(n=18)$ & July & 21.0 & 12.4 & 29.4 & 58 & 7.3 \\
\hline \multirow{2}{*}{ Ural } & August & 21.5 & 11.9 & 31.6 & 56 & 55.0 \\
$(n=13)$ & June & 18.4 & 8.5 & 27.6 & 63 & 48.5 \\
& July & 17.3 & 8.8 & 25.6 & 71 & 26.8 \\
\hline \multirow{2}{*}{ West Siberia } & August & 18.0 & 8.7 & 28.1 & 71 & 32.9 \\
$(n=26)$ & June & 18.6 & 9.1 & 28.0 & 60 & 45.6 \\
& July & 19.6 & 11.8 & 28.0 & 71 & 34.5 \\
\hline
\end{tabular}

\subsection{Isolation and Morphological Characterization of Fusarium spp. in Wheat Grain}

The 100-150 grains of each sample were surface sterilized with a 5\% sodium hypochlorite solution for 1-3 min. Then, the grains were washed with sterile water and put into Petri dishes on self-made potato sucrose agar medium (PSA) containing $1 \mathrm{~mL} / \mathrm{L}$ of a mixture of antibiotics (HyClone $\mathrm{TM}$, GE Healthcare Life Sciences, Wien, Austria), which suppressed the growth of bacteria, and $0.4 \mu \mathrm{L} / \mathrm{L}$ of Triton X-100 solution (Panreac, Barcelona, Spain), which reduced the linear growth of mycelial fungi. After 7 days of incubation in the dark at $24^{\circ} \mathrm{C}$, the number and the species composition of the fungi were counted and identified. The taxonomic status of isolated fungi was determined according to the sum of their morphological features [49]. The grain infection by the principal toxigenic Fusarium species (F. graminearum and F. sporotrichioides) was calculated as the ratio of the number of grains from which these fungi were isolated to the total number of analyzed grains and expressed as the incidence percentage.

\subsection{Sample Preparation for Molecular and Biochemical Analysis}

All of the grain samples ( $20 \mathrm{~g}$ ) were homogenized separately in sterilized grinding chambers of a batch mill Tube Mill Control (IKA, Königswinter, Germany). The speed of grain grinding was $20,000 \mathrm{rpm}$ for $1 \mathrm{~min}$. The ground wheat flour was stored at $-20^{\circ} \mathrm{C}$ until further analyses.

\subsection{DNA Extraction and Quantitative PCR}

The total DNA from $200 \mathrm{mg}$ of wheat flour was isolated using the Genomic DNA Purification Kit (Thermo Fisher Scientific, Vilnus, Lithuania) based on a modification of the manufacturer's protocol. Using the same kit, DNA was also isolated from the mycelium of typical strains of F. graminearum and F. sporotrichioides cultivated on PSA. All the typical strains of fungi are maintained in the Collection of the Laboratory of Mycology and Phytopathology of the All-Russian Institute of Plant Protection (St. Petersburg, Russia).

The quality of the fungal DNA was checked with the primer pair ITS1/ITS4 [50]. DNA concentrations from the grain samples and fungal isolates were determined using a Qubit 2.0 Fluorometer with a Quant-iT dsDNA HS Assay Kit (Thermo Fisher Scientific, Waltham, MA, USA). Before the start of qPCR, the concentrations of all DNA samples were aligned to $20-85 \mathrm{ng} / \mu \mathrm{L}$.

The amount of $F$. graminearum and F. sporotrichioides DNA was determined in every total DNA sample. The DNA content of the F. graminearum was evaluated by qPCR with TaqMan probes [13]. The reaction was carried out in a $20 \mu \mathrm{L}$ volume containing $10 \mu \mathrm{L}$ of a $2 \times$ TaqM master mix (AlkorBio, St.Petersburg, Russia), $300 \mathrm{nM}$ of each primer, $100 \mathrm{nM}$ of a fluorescent sample (Evrogen, Moscow, Russia), and $2 \mu \mathrm{L}$ of the corresponding DNA solution.

The DNA content of $F$. sporotrichioides was determined using qPCR with SYBR Green dye [13]. The reaction was carried out in a $20 \mu \mathrm{L}$ volume containing $4 \mu \mathrm{L}$ of a $5 \times$ qPCRmix-HS SYBR master mix (Evrogen, Moscow, Russia), $500 \mathrm{nM}$ of each primer, and $2 \mu \mathrm{L}$ of the DNA solution. 
All qPCR assays were run using the CFX 96 Real-Time System thermocycler (BioRad, Hercules, CA, USA). The DNA solutions of the Fusarium strains were diluted to $10 \mathrm{ng} / \mu \mathrm{L}$ and used to construct calibration curves in subsequent dilutions of factors of 10 from $10^{-1}$ to $10^{-6} \mathrm{ng} / \mu \mathrm{L}$. Fold-differences and standard errors were calculated from the $\mathrm{Ct}$ values, which were normalized against the DNA of pure cultures of F. graminearum and F. sporotrichioides using the Bio-Rad CFX Manager 1.6 software package. DNA content was presented as the ratio of fungal DNA to total DNA in each sample (pg/ng). The low quantification limit of $5 \times 10^{-4} \mathrm{pg}$ fungal DNA on one ng of total DNA was established as the threshold value of DNA in a sample, which can be quantitatively determined with high precision. All samples were analyzed at least twice.

\subsection{Immunoassays for Detection of Fusarium Biomass}

The extraction was carried out from $1 \mathrm{~g}$ of wheat flour by extensive mixing with $0.1 \mathrm{M}$ phosphate-buffered saline (pH 7.2-7.4) at 1:10 (w/v) on the shaker platform ST-3L (ELMI, Riga, Latvia) for $30 \mathrm{~min}$ at ambient temperature $\left(+20-25^{\circ} \mathrm{C}\right)$. Then, the extracts were cleared by centrifugation for $15 \mathrm{~min}$ at $3000 \times \mathrm{g}$ at $+2-8^{\circ} \mathrm{C}$ (GPR centrifuge, Beckman, USA). The obtained supernatants were analyzed immediately or stored at $-20^{\circ} \mathrm{C}$ until further analyses. In the case of testing a frozen extract, it was first centrifuged following the same procedure, and then the secondary supernatant was used for the analysis.

In the EIA competition format (XEMA, cat\# K827L, Moscow, Russia), the flour extract was incubated in a microwell coated with the antigen (fungal extract) along with the specific affinity-purified rabbit polyclonal antibodies. After washing the unbound material, the remaining antibodies were detected using an anti-rabbit-horseradish peroxidase conjugate tracer. The chromogenic reaction signal is inversely related to the concentration of fungal antigens in the sample. The EIA required undiluted grain extracts and was quantitated in units/mL using calibration samples supplied with the assay kits.

\subsection{Mycotoxin Analysis}

ELISA kits of XEMA Co. Ltd. (Moscow, Russia) were used for the analysis of DON (cat. No. K925), ZEN (cat. No. K923) and T-2 toxin (cat. No. K922). Mycotoxin extraction and next-sample pretreatment for each immunoassay kit were performed according to the manufacturer's instructions. The absorbance of the final solutions was measured with a spectrophotometer (Multiskan EX, Thermo Electron Corporation, Vantaa, Finland) at $450 \mathrm{~nm}$.

HPLC-MS/MS system-tandem liquid chromatography-mass spectrometry was used for the validation of the immunoassay methods (Agilent Infinity LC Systems 1290 and AB SCIEX Triple Quad тм 5500). The analysis of the mycotoxins was carried out in the laboratory of the All-Russian Scientific and Technological Institute of Poultry (Moscow region), with the support of the Russian branch of the company Biomin, following the described procedure [51]. From every sample $5 \mathrm{~g}$ of wheat flour was extracted with $20 \mathrm{~mL}$ of extraction solvent (acetonitrile/water/acetic acid 79:20:1, v/v/v). Detection and quantification were performed with a QTrap 5500MS/MS system (Applied Biosystems, Foster City, CA) equipped with a TurboV electrospray ionization (ESI) source and a 1290 series UHPLC system (Agilent Technologies, Waldbronn, Germany). Chromatographic separation was performed at $25^{\circ} \mathrm{C}$ on a Gemini ${ }^{\circledR} \mathrm{C} 18$-column, $150 \times 4.6 \mathrm{~mm}$ i.d., with a $5 \mu \mathrm{m}$ particle size, equipped with a $\mathrm{C} 18$ security guard cartridge, $4 \times 3 \mathrm{~mm}$ i.d. (all from Phenomenex, Torrance, CA, US). Elution was carried out in binary gradient mode. Both mobile phases contained $5 \mathrm{mM}$ ammonium acetate and were composed of methanol/water/acetic acid ratios of 10:89:1 (v/v/v; eluent $A)$ and 97:2:1 (v/v/v; eluent B), respectively.

The limit of detection (LOD) determined for each mycotoxin was 4.9, 0.8, 3.25 and $2.7 \mathrm{ppb}$ for DON, ZEN, T-2, and HT-2 toxins, respectively. Concerning the limits of quantification (LOQ), they varied in case of DON in range of 5.8-215.2 ppb, ZEN-1.1-40.8 ppb, T-2 toxin-5.23-193.6 ppb, and HT-2 toxin-3.48-129.2 ppb. 
Regardless of the method of mycotoxin analysis, the extracts exceeding the upper limits of mycotoxin detection were diluted and reanalyzed, and the dilution factor has been used for calculations of the concentrations of mycotoxins. All samples were analyzed at least twice.

\subsection{Statistical Analysis}

Data were analyzed using Microsoft Office Excel 2010 (Microsoft, Redmond, WA, USA) and Statistica 10.0 (StatSoft, Tulsa, OK, USA). To center the distribution of quantitative parameters, in addition to the mean, the median was also calculated. Since the original data did not assume normal distribution, the Mann-Whitney $U$ test, non-parametric alternative of $t$-test, was used to test whether the medians of samples are different $(p \leq 0.05)$ [52]. The relationship between the quantitative traits was evaluated using the linear Pearson correlation coefficient $(r)$ at a significance level of $p \leq 0.01$.

Supplementary Materials: The following are available online at http://www.mdpi.com/2072-6651/11/5/252/s1. Table S1: List of the results obtained with the various analytical methods.

Author Contributions: Conceptualization, T.G.; Data curation, O.G. and A.O.; Formal analysis, O.G., A.O. and Y.L.; Funding acquisition, S.E.; Investigation, T.G., O.G., A.O., I.S. and P.P.; Methodology, T.G., A.O. and Y.L.; Project administration, Y.L. and S.E.; Resources, Y.L.; Supervision, T.G.; Validation, T.G., O.G. and Y.L.; Visualization, O.G. and A.O.; Writing-original draft, T.G.; Writing-review \& editing, O.G., A.O., Y.L. and S.E.

Funding: This research was financially supported by the Ministry of Education and Science of the Russian Federation (unique identifier of project: RFMEFI60717X0185).

Acknowledgments: We are grateful to the managers of the Russian Branch of Syngenta (Moscow) for their help with the grain sample collection and to N. Gogina from the All-Russian Scientific and Technological Institute of Poultry (Moscow region) for carrying out HPLC-MS/MS analysis.

Conflicts of Interest: The authors declare no conflict of interest. The funders had no role in the design of the study; in the collection, analyses, and interpretation of data; in the writing of the manuscript; or in the decision to publish the results.

\section{References}

1. Vogelgsang, S.; Sulyok, M.; Bänziger, I.; Krska, R.; Schuhmacher, R.; Forrer, H.R. Effect of fungal strain and cereal substrate on in vitro mycotoxin production by Fusarium poae and Fusarium avenaceum. Food Addit. Contam. Part A 2008, 25, 745-757. [CrossRef]

2. Chandelier, A.; Nimal, C.; André, F.; Planchon, V.; Oger, R. Fusarium species and DON contamination associated with head blight in winter wheat over a 7-year period (2003-2009) in Belgium. Eur. J. Plant Pathol. 2011, 130, 403-414. [CrossRef]

3. Nazari, L.; Pattori, E.; Somma, S.; Manstretta, V.; Waalwijk, C.; Moretti, A.; Meca, G.; Rossi, V. Infection incidence, kernel colonisation, and mycotoxin accumulation in durum wheat inoculated with Fusarium sporotrichioides, F. langsethiae or F. poae at different growth stages. Eur. J. Plant Pathol. 2019, 153, 715-729. [CrossRef]

4. Nicolaisen, M.; Suproniene, S.; Nielsen, L.K.; Lazzaro, I.; Spliid, N.H.; Justesen, A.F. Real-time PCR for quantification of eleven individual Fusarium species in cereals. J. Microbiol. Methods 2009, 76, 234-240. [CrossRef] [PubMed]

5. Boutigny, A.-L.; Gautier, A.; Basler, R.; Dauthieux, F.; Leite, S.; Valade, R.; Aguayo, J.; Ioos, R.; Laval, V. Metabarcoding targeting the EF1 alpha region to assess Fusarium diversity on cereals. PLOS ONE 2019, 14, e0207988. [CrossRef] [PubMed]

6. Torp, M.; Nirenberg, H.I. Fusarium langsethiae sp. nov. on cereals in Europe. Int. J. Food Microb 2004, 95, 247-256. [CrossRef] [PubMed]

7. $\mathrm{Xu}, \mathrm{X}$; Nicholson, P. Community ecology of fungal pathogens causing wheat head blight. Annu Rev. Phytopathol. 2009, 47, 83-103. [CrossRef] [PubMed]

8. Hofgaard, I.S.; Aamot, H.U.; Torp, T.; Jestoi, M.; Lattanzio, V.M.T.; Klemsdal, S.S.; Waalwijk, C.; van der Lee, T.; Brodal, G. Associations between Fusarium species and mycotoxins in oats and spring wheat from farmers' fields in Norway over a six-year period. World Mycotoxin J. 2016, 9, 365-378. [CrossRef]

9. McCormick, S.P.; Stanley, A.M.; Stover, N.A.; Alexander, N.J. Trichothecenes: From simple to complex mycotoxins. Toxins 2011, 3, 802-814. [CrossRef] 
10. Wolf, J.C.; Mirocha, C.J. Regulation of sexual reproduction in Gibberella zeae (Fusarium roseum 'Graminearum') by F-2 (zearalenone). Can. J. Microbiol. 1973, 19, 725-734. [CrossRef]

11. Moretti, A.; Pascale, M.; Logrieco, A.F. Mycotoxin risks under a climate change scenario in Europe. Trends Food Sci. Technol. 2019, 84, 38-40. [CrossRef]

12. Technical regulations of the Eurasian Economic (Customs) Union \#021/2011 «About food safety». Available online: http://www.tsouz.ru/db/techreglam/Documents/TR\%20TS\%20PishevayaProd.pdf (accessed on 18 March 2019).

13. Yli-Mattila, T.; Paavanen-Huhtala, S.; Parikka, P.; Hietaniemi, V.; Jestoi, M.; Gagkaeva, T.; Sarlin, T.; Haikara, A.; Laaksonen, S.; Rizzo, A. Real-time PCR detection and quantification of Fusarium poae, F. graminearum, F. sporotrichioides and F. langsethiae as compared to mycotoxin production in grains in Finland and Russia. Arch. Phytopath Plant. Protect. 2008, 41, 243-260. [CrossRef]

14. Gagkaeva, T.Yu.; Orina, A.S.; Gavrilova, O.P.; Ablova, I.B.; Bespalova, L.A. Characterization of resistance of winter wheat varieties to Fusarium head blight. Vavilov J. Genet. Breed. 2018, 22, 685-692. [CrossRef]

15. Nicholson, P.; Chandler, E.; Draeger, R.C.; Gosman, N.E.; Simpson, D.R.; Thomsett, M.; Wilson, A.H. Molecular tools to study epidemiology and toxicology of Fusarium head blight of cereals. Eur. J. Plant. Pathol. 2003, 109, 691-703. [CrossRef]

16. Waalwijk, C.; van der Heide, R.; de Vries, I.; van der Lee, T.; Schoen, C.; Corainville, G.-C.; Hauser-Hahn, I.; Kastelein, P.; Kohl, J.; Lonnet, P.; et al. Quantitative detection of Fusarium species in wheat using TaqMan. Eur. J. Plant. Pathol. 2004, 110, 481-494. [CrossRef]

17. Fredlund, E.; Gidlund, A.; Olsen, M.; Börjesson, T.; Spliid, N.H.; Simonsson, M. Method evaluation of Fusarium DNA extraction from mycelia and wheat for down-stream real-time PCR quantification and correlation to mycotoxin levels. J. Microbiol. Methods 2008, 73, 33-40. [CrossRef] [PubMed]

18. Kwak, B.-Y.; Kwon, B.-J.; Kweon, C.-H.; Shon, D.-H. Detection of Fusarium species by enzyme-linked immunosorbent assay using monoclonal antibody. J. Microbiol. Biotechnol. 2003, 13, 794-799.

19. Kwak, B.-Y.; Kwon, B.-J.; Kweon, C.-H.; Shon, D.-H. Detection of Aspergillus, Penicillium, and Fusarium species by sandwich enzyme-linked immunosorbent assay using mixed monoclonal antibodies. J. Microbiol. Biotechnol. 2004, 14, 385-389.

20. Gannibal, Ph.B.; Grachev, A.V.; Kozhevnikov, E.A.; Lebedin, Yu.S. Immunoassay analysis of seeds contamination by fungi from the genus Alternaria. Mikologiya I Fitopatologiya 2010, 44, 463-471. (In Russian)

21. Omori, A.M.; Ono, E.Y.S.; Hirozawa, M.T.; de Souza Suguiura, I.M.; Hirooka, E.Y.; Pelegrinelli Fungaro, M.H.; Ono, M.A. Development of indirect competitive enzyme-linked immunosorbent assay to detect Fusarium verticillioides in poultry feed samples. Toxins 2019, 11, 48. [CrossRef] [PubMed]

22. Prieto-Simón, B.; Noguer, T.; Campàs, M. Emerging biotools for assessment of mycotoxins in the past decade. Trends Anal. Chem. 2007, 26, 689-702. [CrossRef]

23. Goryacheva, I.Y.; De Saeger, S.; Eremin, S.A.; Van Peteghem, C. Immunochemical methods for rapid mycotoxin detection: Evolution from single to multiple analyte screening: A review. Food Addit. Contam. Part A Chem. Anal. Control. Expo. Risk Assess. 2007, 24, 1169-1183. [CrossRef]

24. Krska, R.; Schubert-Ullrich, P.; Molinelli, A.; Sulyok, M.; MacDonald, S.; Crews, C. Mycotoxin analysis: An update. Food Addit. Contam. Part A Chem. Anal. Control. Expo. Risk Assess. 2008, 25, 152-163. [CrossRef] [PubMed]

25. Maragos, C.M.; Busman, M. Rapid and advanced tools for mycotoxin analysis: A review. Food Addit. Contam. Part A Chem Anal. Control. Expo. Risk Assess. 2010, 27, 688-700. [CrossRef]

26. Turner, N.W.; Bramhmbhatt, H.; Szabo-Vezse, M.; Poma, A.; Coker, R.; Piletsky, S.A. Analytical methods for determination of mycotoxins: An update (2009-2014). Anal. Chim Acta 2015, 901, 12-33. [CrossRef] [PubMed]

27. Berthiller, F.; Cramer, B.; Iha, M.H.; Krska, R.; Lattanzio, V.M.T.; MacDonald, S.; Malone, R.J.; Maragos, C.; Solfrizzo, M.; Stranska-Zachariasova, M.; et al. Developments in mycotoxin analysis: An update for 2016-2017. World Mycotoxin J. 2018, 11, 5-32. [CrossRef]

28. Yli-Mattila, T.; Gagkaeva, T.; Ward, T.J.; Aoki, T.; Kistler, H.C.; O’Donnell, K. A novel Asian clade within the Fusarium graminearum species complex includes a newly discovered cereal head blight pathogen from the Far East of Russia. Mycologia 2009, 101, 841-852. [CrossRef] [PubMed] 
29. Yli-Mattila, T.; Gagkaeva, T. Molecular chemotyping of Fusarium graminearum, F. culmorum, and F. cerealis isolates from Finland and Russia. In Molecular Identification of Fungi; Gherbawy, Y., Voigt, K., Eds.; Springer: Berlin, Germany, 2010; pp. 159-177.

30. Ivashchenko, V.G.; Shipilova, N.P.; Levitin, M.M. Species composition of Fusarium fungi on cereals in the Asian part of Russia. Mikologiya I Fitopatologiya 2000, 34, 54-68.

31. Gagkaeva, T.Y.; Yli-Mattila, T. Genetic diversity of Fusarium graminearum in Europe and Asia. Eur. J. Plant. Pathol. 2004, 110, 551-562. [CrossRef]

32. Litovka, Yu.A. The species composition and representation of Fusarium fungi on cereals (wheat and barley) grown in the conditions of Central Siberia. Bull. Krasnoyarsk State Agrar. Univ. 2017, 6, 140-149. (In Russian)

33. Paterson, R.R.; Lima, N. How will climate change affect mycotoxins in food? Food Res. Int 2010, 43, 1902-1914. [CrossRef]

34. Parry, D.W.; Jenkinson, P.; McLeod, L. Fusarium ear blight (scab) in small grain cereals-A review. Plant. Pathol. 1995, 44, 207-238. [CrossRef]

35. Kelly, A.C.; Clear, R.M.; O’Donnell, K.; McCormick, S.; Turkington, T.K.; Tekauz, A.; Gilbert, J.; Kistler, H.C.; Busman, M.; Ward, T.J. Diversity of Fusarium head blight populations and trichothecene toxin types reveals regional differences in pathogen composition and temporal dynamics. Fungal Genet. Biol. 2015, 82, $22-31$. [CrossRef] [PubMed]

36. Sarkisov, A.Ch. Overwintered Cereals Under the Snow; Ministry of Agriculture: Moscow, Russian, $1948 ;$ p. 108.

37. Kononenko, G.P.; Burkin, A.A. Fusariotoxins in cereal feeds. Vet. Pathol. 2002, 2, 128-132.

38. Kononenko, G.P.; Burkin, A.A.; Zotova, E.V.; Ustyuzhanina, M.I.; Smirnov, A.M. Specificity of wheat and barley contamination of grain with fusariotoxins. Russ. Agric. Sci. 2018, 1, 17-21.

39. Fredlund, E.; Gidlund, A.; Pettersson, H.; Olsen, M.; Börjesson, T. Real-time PCR detection of Fusarium species in Swedish oats and correlation to T-2 and HT-2 toxin content. World Mycotoxin J. 2010, 3, 77-88. [CrossRef]

40. Yli-Mattila, T.; Ward, T.J.; O’Donnell, K.; Proctor, R.H.; Burkin, A.A.; Kononenko, G.P.; Gavrilova, O.P.; Aoki, T.; McCormick, S.P.; Gagkaeva, T.Yu. Fusarium sibiricum sp. nov, a novel type A trichothecene-producing Fusarium from northern Asia closely related to F. sporotrichioides and F. langsethiae. Int. J. Food Microbiol. 2011, 147, 58-68. [CrossRef]

41. Yli-Mattila, T.; Gavrilova, O.; Hussien, T.; Gagkaeva, T. Identification of the first Fusarium sibiricum isolate in Iran and Fusarium langsethiae isolate in Siberia by morphology and species-specific primers. J. Plant. Pathol. 2015, 97, 183-187.

42. Pinson-Gadais, L.; Barreau, Ch.; Chaurand, M.; Gregoire, S.; Monmarson, M.; Richard-Forget, F. Distribution of toxigenic Fusarium spp. and mycotoxin production in milling fractions of durum wheat. Food Addit. Contam. Part A Chem. Anal. Control. Expo. Risk Assess. 2007, 24, 53-62. [CrossRef] [PubMed]

43. Horevaj, P.; Milus, E.A.; Bluhm, B.H. A real-time qPCR assay to quantify Fusarium graminearum biomass in wheat kernels. J. Appl. Microbiol. 2011, 111, 396-406. [CrossRef] [PubMed]

44. Strub, C.; Pocaznoi, D.; Lebrihi, A.; Fournier, R.; Mathieu, F. Influence of barley malting operating parameters on T-2 and HT-2 toxinogenesis of Fusarium langsethiae, a worrying contaminant of malting barley in Europe. Food Addit. Contam. A 2010, 27, 1247-1252. [CrossRef]

45. Medina, A.; Magan, N. Temperature and water activity effects on production of T-2 and HT-2 by Fusarium langsethiae strains from north European countries. Food Microbiol. 2011, 28, 392-398. [CrossRef]

46. Kokkonen, M.; Medina, A.; Magan, N. Comparative study of water and temperature relations of growth and T-2/HT-2 toxin production by strains of Fusarium sporotrichioides and Fusarium langsethiae. World Mycotoxin J. 2012, 5, 365-372. [CrossRef]

47. Gavrilova, O.P.; Skritnika, A.; Gagkaeva, T.Yu. Identification and characterization of spontaneous auxotrophic mutants in Fusarium langsethiae. Microorganisms 2017, 5, 14. [CrossRef] [PubMed]

48. Shi, W.; Tan, Y.; Wang, S.; Gardiner, D.M.; De Saeger, S.; Liao, Y.; Wang, C.; Fan, Y.; Wang, Z.; Wu, A. Mycotoxigenic potentials of Fusarium species in various culture matrices revealed by mycotoxin profiling. Toxins 2017, 9, 6. [CrossRef]

49. Gerlach, W.; Nirenberg, H.I. The genus Fusarium-A Pictorial Atlas. In Mitteilungen aus der Biologischen Bundesanstalt fur Land- und Forstwirtschaft, Berlin-Dahlem; Herausgegeben von der Biologischen Bundesanstalt für Land- und Forstwirtschaft: Germany, 1982. 
50. White, T.; Bruns, T.; Lee, S.; Taylor, J. Amplification and direct sequencing of fungal ribosomal RNA genes for phylogenetics. In PCR Protocols: A Guide to Methods and Applications; Innis, M., Gelfand, D., Sninsky, J., White, T., Eds.; Academic Press: Orlando, FL, USA, 1990; Volume 38, pp. 315-322.

51. Malachová, A.; Sulyok, M.; Beltrán, E.; Berthiller, F.; Krska, R. Optimization and validation of a quantitative liquid chromatography-tandem mass spectrometric method covering 295 bacterial and fungal metabolites including all regulated mycotoxins in four model food matrices. J. Chromatogr. A 2014, 1362, 145-156. [CrossRef] [PubMed]

52. Hammer, Ø.; Harper, D.A.T.; Ryan, P.D. PAST: Paleontological statistics software package for education and data analysis. Palaeontol. Electron. 2001, 4, 178kb.

(C) 2019 by the authors. Licensee MDPI, Basel, Switzerland. This article is an open access article distributed under the terms and conditions of the Creative Commons Attribution (CC BY) license (http://creativecommons.org/licenses/by/4.0/). 